\title{
PENINGKATAN FASILITAS TAMAN BACA RPTRA ABDI PRAJA PESANGGRAHAN - JAKARTA SELATAN
}

\author{
Nina Carina ${ }^{1}$, Diah Anggraini ${ }^{2}$, Mekar Sari Suteja ${ }^{3}$ dan Maria Veronica Gandha $^{4}$
}

\author{
${ }^{1}$ Jurusan Arsitektur, F.T., Universitas Tarumanagara Jakarta \\ Email: ninac@ft,untar.ac.id \\ 2 Jurusan Arsitektur, F.T., Universitas Tarumanagara Jakarta \\ Email: diaha@ft.untar.ac.id \\ ${ }^{3}$ Jurusan Arsitektur, F.T., Universitas Tarumanagara Jakarta \\ Email: mekar.ss@gmail.com \\ ${ }^{4}$ Jurusan Arsitektur, F.T., Universitas Tarumanagara Jakarta \\ Email: v_gandha.yahoo.com
}

\begin{abstract}
Parks initially had two functions, an ecological function or green open space and a passive social function. But along with the changes in the types and patterns of activities and lifestyles, and also because of limited land, a park no longer only bears these two functions but will be empowered to become a park with a variety of interactive community functions. For this reason, the DKI Jakarta Provincial Government has decided to develop a public space that functions more than just green space, called the RPTRA (Child Friendly Integrated Public Space). The addition of the concept of child-friendly is a form of government commitment to improve the quality of life of the community, especially families and children. This paper is the result of a study in the context of carrying out community engagement activities with the target of improving reading park facilities in the Abdi Praja RPTRA, Pesanggrahan Village, South Jakarta. The method of implementation refers to a participatory approach, by exploring the perceived problems of Partners, the views of citizens, hopes for the existence of the current Abdi Praja RPTRA, to then be identified and sought a joint solution to overcome the existing problems. This activity resulted in the addition of collections, education to children in RPTRA in the form of training in coloring and puzzle making. In addition, the provision of workshops can make RPTRA closer and beneficial for visitors of childhood. The addition of an interesting collection of books also the addition of educational children's educational tools in the form of puzzles made by children in fact makes the park more often visited and used as its function
\end{abstract}

Keywords: RPTRA Abdi Praja; Participatory; Children's Game Equipment; Puzzle; book collection.

Taman pada awalnya memiliki dua fungsi, yaitu fungsi ekologis atau ruang terbuka hijau dan fungsi sosial yang bersifat pasif. Namun seiring dengan adanya perubahan jenis dan pola aktivitas serta gaya hidup, dan juga karena adanya keterbatasan lahan, maka sebuah taman tidak lagi hanya menyandang dua fungsi tersebut namun akan diberdayakan menjadi sebuah taman dengan fungsi komunitas interaktif ragam fungsi. Untuk itu Pemprov DKI Jakarta memutuskan mengembangkan ruang publik yang berfungsi lebih dari sekedar RTH, dengan sebutan RPTRA (Ruang Publik Terpadu Ramah Anak). Penambahan konsep ramah anak merupakan wujud komitmen pemerintah dalam meningkatkan kualitas hidup masyarakat, khususnya keluarga dan anak. Tulisan ini merupakan hasil kajian dalam rangka pelaksanaan kegiatan pengabdian masyarakat dengan target peningkatan fasilitas taman baca di RPTRA Abdi Praja, Kelurahan Pesanggrahan, Jakarta Selatan. Metode pelaksanaannya mengacu pada pendekatan partisipatif, dengan menggali permasalahan Mitra yang dirasakan, pandangan warga, harapan terhadap keberadaan RPTRA Abdi Praja saat ini, untuk kemudian diidentifasi dan dicarikan solusi bersama untuk mengatasi persoalan yang ada. Kegiatan ini menghasilkan penambahan koleksi, edukasi kepada anak-anak di RPTRA berupa pelatihan proses mewarnai dan pembuatan puzzle. Selain itu pengadaan workshop dapat membuat RPTRA menjadi lebih dekat serta bermanfaat bagi pengunjung usia kanak-kanak. Penambahan koleksi buku yang menarik juga penambahan alat permaianan anak edukatif berupa puzzle yang dibuat sendiri oleh anak-anak secara nyata membuat taman baca lebih sering dikunjungi dan dimanfaatkan sebagaimana fungsinya

Kata kunci: RPTRA Abdi Praja; Partisipatif; Alat Permainan Anak; Puzzle; koleksi buku 


\section{PENDAHULUAN}

Ruang Publik Terpadu Ramah Anak merupakan program yang diluncurkan pemerintah pada tahun 2015 sebagai suatu kebijakan baru untuk merevitalisasi fungsi sebuah taman. Taman pada awalnya memiliki dua fungsi, yaitu fungsi ekologis atau ruang terbuka hijau dan fungsi sosial yang bersifat pasif. Namun seiring dengan adanya perubahan jenis dan pola aktivitas serta gaya hidup, dan juga karena adanya keterbatasan lahan maka sebuah taman tidak lagi hanya menyandang dua fungsi tersebut namun akan diberdayakan menjadi sebuah taman dengan fungsi komunitas interaktif ragam fungsi. Isu yang diangkat pada awalnya adalah kenyataan akan kurangnya ruang bermain anak di Kota Jakarta. Upaya revitalisasi fungsi taman ini didasari atas kurangnya ruang publik yang berfungsi sebagai pusat kegiatan masyarakat dan area evakuasi dalam konteks mitigasi bencana. Untuk itu pemerintah memutuskan mengembangkan ruang publik yang berfungsi lebih dari sekedar RTH, dengan sebutan RPTRA (Ruang Publik Terpadu Ramah Anak). Penambahan konsep ramah anak merupakan wujud komitmen pemerintah dalam meningkatkan kualitas hidup masyarakat, khususnya keluarga dan anak.

Tulisan ini merupakan hasil kajian dalam rangka pelaksanaan kegiatan pengabdian masyarakat yaitu Peningkatan Fasilitas Taman Baca RPTRA Abdi Praja di Kelurahan Pesanggrahan, Jakarta Selatan. RPTRA Abdi Praja yang diresmikan pada Rabu, 03 Januari 2018 berlokasi di Jl. Ulujami Raya, Gang Pancoran, RT 14 RW 01, Kelurahan Pesanggrahan, Kecamatan Pesanggrahan, Jakarta Selatan. Berada di lahan seluas sekitar $1500 \mathrm{~m} 2$. Pada sisi Timur terdapat lahan milik Dinas Pertamanan dan Pemakaman DKI Jakarta yang dapat diolah sebagai kebun warga dan dikelola bersama dengan pengurus RPTRA, hingga seluas lebih dari 1000m2. RPTRA Abdi Praja dipimpin oleh Lurah Pesanggrahan sebagai Ketua, yaitu Ibu Hj. Saryati S dan dikelola oleh Bapak Suwondo selaku koordinator pengelola dengan 5 orang anggotanya.

Sesuai dengan fungsi pelayanannya, RPTRA Abdi Praja dilengkapi dengan fasilitas sebagai berikut: taman baca, warung warga (OK OC), ruang/hall serba guna, tempat bermain anak, taman refleksi dan taman hydroponic, lapangan futsal serta gudang, dapur dan toilet. Lokasi RPTRA Abdi Praja yang strategis, terletak di tepi jalan inspeksi Kali Pesanggrahan dan berada di titik pertemuan antara jalan lingkungan dengan jalan pintas ke arah jalan Veteran (kelas jalan lokal primer) membuat RPTRA tersebut kerap menjadi tempat bagi diadakannya aktvitas pelatihan yang lebih mengutamakan usia dewasa berbanding usia anak-anak. Nilai strategis lokasi juga karena bersisian dengan danau buatan yang diberi nama Danau Bintaro dan sangat dekat dengan danau Cavalio. Kedua danau ini rutin digunakan sebagai tempat bagi pelaksanaan karnaval dan festival skala Kecamatan.

Beberapa pelatihan yang pernah diadakan di RPTRA ini, tidak hanya berskala lokal, namun hingga berskala Kota. Beberapa pelatihan dan aktivitas yang pernah diselenggarakan di RPTRA Abdi Praja dan ditujukan bagi orang dewasa antara lain adalah; Pelatihan Jurnalisme Warga, Pelatihan Pemberdayaan Tenaga Kerja Mandiri Wira Usaha Baru bidang Steam Motor, Pelatihan Tata Boga Bidang Kue Kering, Nonton Bareng Penutupan Asian Games 2018 dan sebagainya.

Permasalahan Mitra adalah aktivitas RPTA lebih sering digunakan untuk berbagai kegiatan bagi orang dewasa. pengelola merasakan perlunya meningkatkan dan mendayagunakan manfaat RPTRA Abdi Praja bagi warga sekitar khususnya anak-anak. Manfaat RPTRA bagi usia kanakkanak seharusnya tidak hanya diwujudkan dalam bentuk penyediaan ruang terbuka dan ruang bermain namun juga sebagai ruang belajar. Ruang belajar antara lain diwujudkan dengan adanya taman baca sebagai salah satu fungsi dan fasilitas RPTRA. Keberadaan taman baca pada RPTRA Abdi Praja saat ini dirasakan belum berdaya guna sebagaimana seharusnya. Kondisi taman baca 
lebih sering digunakan para orang tua sebagai tempat menunggu saat anak-anak mereka bermain di ruang terbuka.

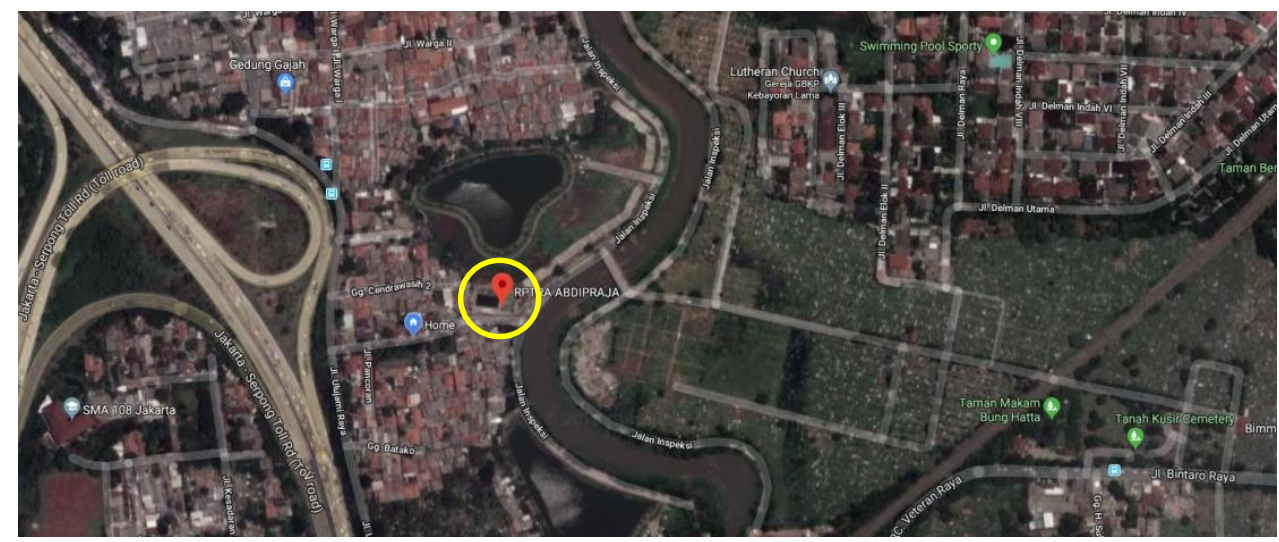

Gambar 1. Peta Lokasi RPTRA Abdi Praja

Sumber : Google map/ satelite, Oktober 2018

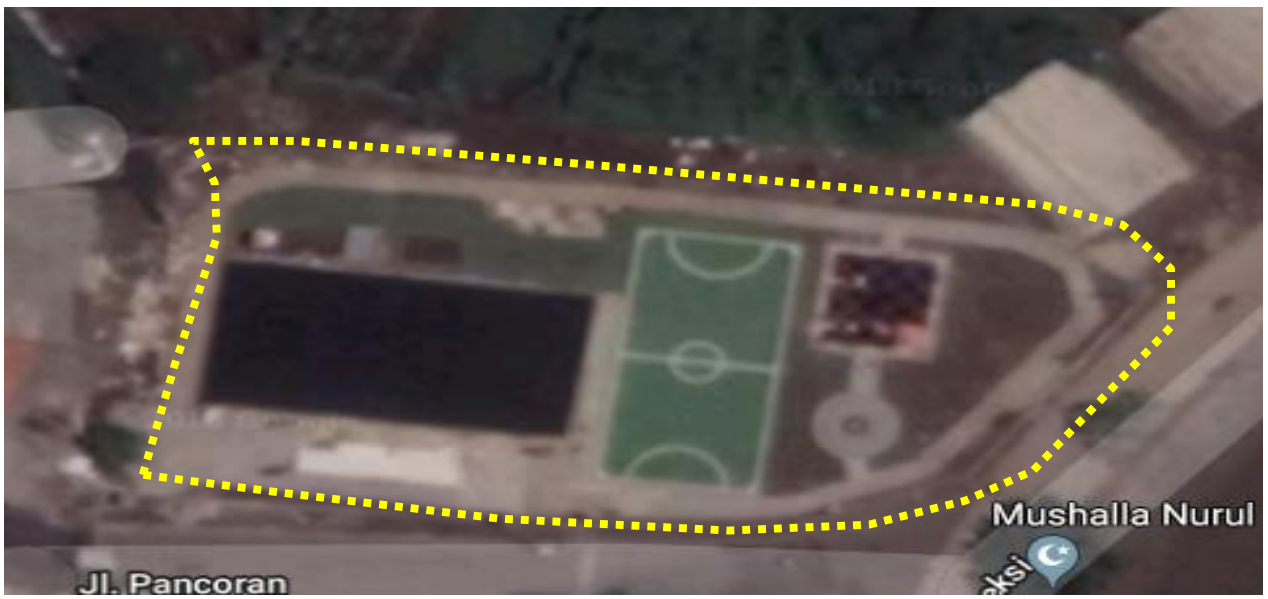

Gambar 2. Peta Situasi RPTRA Abdi Praja

Sumber : Google map/ satelite, Oktober 2018

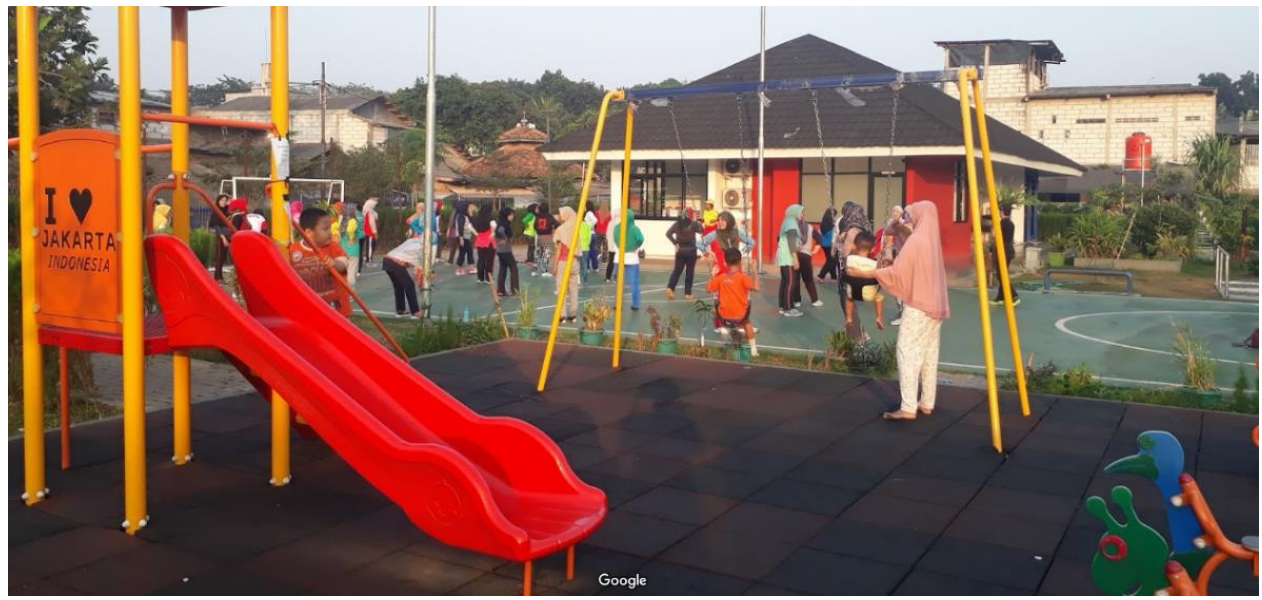

Gambar 3. Suasana RPTRA Abdi Praja

Sumber : pribadi 


\section{KAJIAN PUSTAKA}

\section{Ruang Publik Ramah Anak}

Kebutuhan RPTRA bagi kota Jakarta didasarkan atas dua hal besar yaitu: (Oscar M. Mungkasa, Deputi Gub, DKI bidang Tata Ruang dan Lingkungan Hidup, dalam paparan berjudul Ruang Publik Terpadu Ramah Anak; Konsep, Implementasi dan Pembelajaran, Jakarta 18 Agustus 2017)

1. Kebutuhan ruang sosialisasi anak (untuk kebutuhan bermain, belajar dan berinteraksi), serta

2. Kebutuhan interaksi sosial bagi masyarakat, khususnya keluarga (konseling keluarga, program Keluarga Berencana dan peningkatan kesejahteraan).

Visi dari RPTRA adalah menuju masyarakat yang harmonis, sedangkan misi yang diemban adalah menjadi kota layak anak. Dengan dasar tersebut sebuah RPTRA direncanakan, dirancang dan dibuat untuk dapat mengakomodasi fungsi-fungsi berikut:

1) Pusat kegiatan masyarakat yaitu menjadi pusat kegiatan ekonomi dan sosial;

2) Penyediaan sarana pelayanan dan kegiatan terpadu dari bayi sampai lansia, yaitu menjadi pusat konsultasi dan informasi keluarga;

3) Penyediaan fasilitas terpadu anak di luar sekolah termasuk disabilitas, yaitu menjadi tempat bermain anak dan taman publik;

4) Ruang terbuka hijau dan penyerapan air tanah, yaitu menjadi konservasi akhir;

5) Kawasan evakuasi bencana

Untuk menjadi sebuah taman yang dapat mengakomodir kebutuhan ruang sosialisasi anak dan kebutuhan interaksi sosial bagi masyarakat, maka sebuah RPTRA direncanakan untuk memiliki layanan-layanan sebagai berikut;

1) Layanan Kepada Anak; yang meliputi kegiatan bina keluarga balita dan pendidikan anak usia dini (BKB-PAUD) serta bina keluarga remaja (BKR). Fungsi layanan ini antara lain diterjemahkan menjadi fungsi sebagai berikut:

- Pusat informasi dan konsultasi (PIK) remaja

- Kegiatan Pos Pelayanan Terpadu (Posyandu)

- Perpustakaan Ramah Anak

- Tempat Berolah Raga Anak

- Kegiatan Kreatif Anak

- Kegiatan Forum Anak

2) Layanan Kepada Masyarakat; yang diterjemahkan menjadi fungsi-fungsi berikut:

- Kegiatan 10 program pokok PKK

- PKK MART sebagai wadah ekonomi produktif

- Peringatan hari besar nasional

- Hajatan masyarakat

- Kegiatan olah raga masyarakat

- Kegiatan kesenian dan kebudayaan masyarakat

- Kegiatan pelatihan dan sosialisasi untuk masyarakat

- Kegiatan lansia

- Kegiatan pelayanan kesehatan dan KB

- Pengadan kekerasan perempuan dan anak

- Perpusatakaan

- Laktasi/menyusui 
Layanan kebencanaan; RPTRA pada situasi dan kondisi tertentu dapat dimanfaatkan sebagai tempat penampungan sementara bagi pengungsi, yaitu masyarakat umum korban bencana (perempuan dan anak pada khususnya).

\section{Pendekatan Partisipatif}

Pendekatan partisipatif mulai dikembangkan dalam program-program pembangunan secara umum. Hal ini terjadi karena pada era modernisasi (setelah PD II - 1970an) khususnya yang terjadi di negara-negara berkembang, hasil pembangunan dengan cara top-down seringkali tidak dipahami dan tidak sesuai dengan kebutuhan masyarakat sasaran. Peran pemerintah dan swasta yang dominan tanpa melibatkan masyarakat sasaran juga menyebabkan kepedulian dan rasa memiliki yang rendah dari penggunanya, serta pada akhirnya hasil pembangunan tidak tepat sasaran. Dengan demikian perlu dicari solusi antara lain dengan proses pembangunan bottom-up, dengan konsep bukan lagi membangun untuk rakyat melainkan membangun bersama rakyat. Keterlibatan masyarakat dimulai dari perencanaan kegiatan, persiapan, pelaksanaan, sampai dengan pemanfaatan dan perawatan hasil pembangunan. Dalam arsitektur dikenal dengan istilah participatory design, yaitu pendekatan desain yang berupaya melibatkan para pihak (stakeholders) dalam rangkaian proses desain. Pendekatan desain partisipatif lebih berfokus pada proses dan prosedur desain dan bukan sebuah style atau gaya arsitektur. Dalam satu sisi, pendekatan ini juga berdimensi politis antara lain berkaitan dengan penguatan/empowerment dan demokratisasi, dan di sisi lain hal ini juga berkaitan dengan tanggung jawab arsitek.

\section{Perkembangan Anak}

Masa tumbuh kembang anak dibagi menjadi dua tahap, yaitu masa awal, masa pertengahan dan akhir. Masa awal anak-anak dimulai sejak anak berumur 2 tahun hingga 6 tahun. Masa pertengahan dan akhir dimulai ketika anak memasuki kelas 1 SD atau umur 6 tahun hingga anak menjadi individu yang matang secara seksual. Setiap masa perkembangannya, ciri perkembangan anak berbeda, baik secara motorik, intelektual, maupun sosial. Perkembangan motorik anak pada masa awal ditandai dengan berjalan, berlari, melompat, mendorong, menarik, memutar, berbagai aktivitas koordinasi mata-tangan, menggambar, mewarna, dan mencoret. Pada masa ini anak sudah dapat memanipulasi objek kecil seperti potongan-potongan puzzle dan balok-balok dengan berbagai ukuran dan bentuk.

\section{Perpustakaan Untuk Anak}

Perpustakaan adalah salah satu unit kerja yang berupa tempat untuk mengumpulkan, menyimpan, mengelola, dan mengatur koleksi bahan pustaka secara sistematis untuk digunakan oleh pemakai sebagai sumber informasi sekaligus sebagai sarana belajar yang menyenangkan. Secara umum, perpustakaan memiliki beberapa fungsi, yaitu fungsi informasi, fungsi pendidikan, fungsi kebudayaan, fungsi rekreasi, fungsi penelitian, dan fungsi deposit. ${ }^{1}$

Bagi anak-anak, keberadaan perpustakaan dapat mendorong perkembangan minat baca, namun perlu dipahami karakteristik anak pada setiap tahap usia mereka. Misalnya pada usia 1-3 tahun anak cenderung merobek kertas, sehingga buku yang digunakan sebaiknya adalah yang terbuat dari plastik atau kain, yang tidak mudah robek. Isi bacaan berupa satu macam benda berikut namanya pada setiap halamannya. Pada usia 3-5 tahun, anak memiliki penguasaan bahasa yang jauh lebih baik, sehingga isi buku dapat berupa beberapa kata (kalimat) yang merupakan gagasan, namun tetap dengan ilustrasi gambar yang menarik. Jenis cerita yang digemari adalah yang bersifat fancy, dengan ukuran buku 21 x $29.7 \mathrm{~cm}$. Pada usia 5-7 tahun anak berkembang dalam dunia akademis dan intelektual. Oleh karena itu, yang menonjol adalah banyaknya kata, gagasan, dan

\footnotetext{
*Disarikan dari Wijaya, N.A. dan Tulistyantoro, L (2016)
} 
konsep yang merupakan representasi dari hal yang pernah dialami. Pada usia 7-9 tahun anak berada di sekolah dasar sehingga perkembangan intelektual diarahkan pada bagaimana sekolah melihat sesuatu itu penting. Oleh karena itu, buku-buku yang diberikan merupakan buku ynag dapat membantu pelajaran di sekolah. Cerita yang memberi kesan action juga diminati pada usia ini ${ }^{2}$

\section{Alat Permainan Edukatif}

Alat permainan edukatif (APE) adalah alat permainan yang sengaja dirancang khusus untuk kepentingan pendidikan, alat bantu belajar dan dapat mengoptimalkan perkembangan anak. APE harus disesuaikan dengan usia dan tingkat perkembangannya. Beberapa manfaat mainan edukatif antara lain yaitu melatih kemampuan motorik, melatih konsentrasi, mengembangkan konsep sebab akibat, melatih bahasa dan wawasan, serta mengenalkan warna dan bentuk. Puzzle merupakan salah satu bentuk alat permainan edukatif memenuhi unsur fungsi melatih anak untuk fokus, melatih motorik halus, melatih pengembangan konsep sebab akibat dan melatih pengenalan warna dan bentuk. ${ }^{3}$

\section{Puzzle Untuk Anak dan Teknik Pembuatannya.}

Selain penyediaan buku, dan penataan yang menarik, sebuah taman baca untuk anak juga memerlukan area interaktif. Area ini dapat dilengkapi dengan berbagai sarana untuk menunjang aktivitas kognitif anak, seperti area mendongeng atau bercerita, aktivitas untuk melatih motorik halus misalnya bermain puzzle dan aktivitas sosial yang lain. Sebagai salah satu jenis permainan anak-anak yang digemari, penyediaan dan pembuatan puzzle perlu dilakukan sesuai ketentuan, sehingga dapat sesuai dengan tahap perkembangan anak dan memenuhi aspek keamanan. Menurut SNI ISO 8124-1:2010, butir 3.64 puzzle termasuk dalam kategori mainan (toy) yaitu segala produk atau material yang dirancang atau secara jelas dimaksudkan untuk digunakan bermain oleh anakanak berusia di bawah 14 tahun. Sebagaimana persyaratan keamanan bagi anak-anak, ketika akan membuat puzzle, bahan dasar bagi puzzle harus memenuhi kriteria dan persyaratan bahan dasar bagi pembuatan mainan anak. Sebuah mainan anak tidak boleh mencederai anak, sehingga harus memenuhi syarat sebagai berikut: mudah dalam perawatan; tidak boleh memiliki sudut yang runcing dan membahayakan; tidak menggunakan bahan- bahan beracun; dan memiliki ukuran yang disesuaikan dengan usia penggunanya. Puzzle dapat dibuat dari kayu pinus, kayu karet, kayu sungai mau pun tripleks. Untuk finishing, disyaratkan penggunaan material non toxic baik untuk cat, pelapis cat, serbuk glazur dan polimer. Sementara itu puzzle perlu melalui proses pemotongan sesuai bentuk yang diinginkan dan dilakukan penghalusan.

\section{Warna Primer dan Hue}

Warna termasuk salah satu unsur keindahan dalam seni dan desain selain unsur-unsur visual yang lain. Warna merupakan bagian dari cahaya yang diteruskan atau dipantulkan. Terdapat tiga unsur yang penting dari pengertian warna, yaitu benda, mata dan unsur cahaya. Secara umum, warna didefinisikan sebagai unsur cahaya yang dipantulkan oleh sebuah benda dan selanjutnya diintrepetasikan oleh mata berdasarkan cahaya yang mengenai benda tersebut.

Pada tahun 1831, Brewster mengemukakan teori tentang pengelompokan warna. Teori Brewster membagi warna-warna yang ada di alam menjadi empat kelompok warna, yaitu warna primer, sekunder, tersier, dan netral. Di dalam melaksanakan PKM, tim akan mengenalkan jenis warna primer dan campuran diantara warna primer yang akhirnya membentuk apa yang dikenal dengan warna sekunder dan tertier. Tiga warna utama sebagai dasar dan disebut warna primer, yaitu merah (M), kuning (K), dan biru (B). Apabila warna dua warna primer masing-masing dicampur, maka

\footnotetext{
${ }^{2}$ Disarikan dari Wijaya, N.A. dan Tulistyantoro, L (2016)

${ }^{3}$ Disarikan dari Syamsuardi (2012)
} 
akan menghasilkan warna kedua atau warna sekunder. Bila warna primer dicampur dengan warna sekunder akan 9 dihasilkan warna ketiga atau warna tersier. Bila antara warna tersier dicampur lagi dengan warna primer dan sekunder akan dihasilkan warna netral.

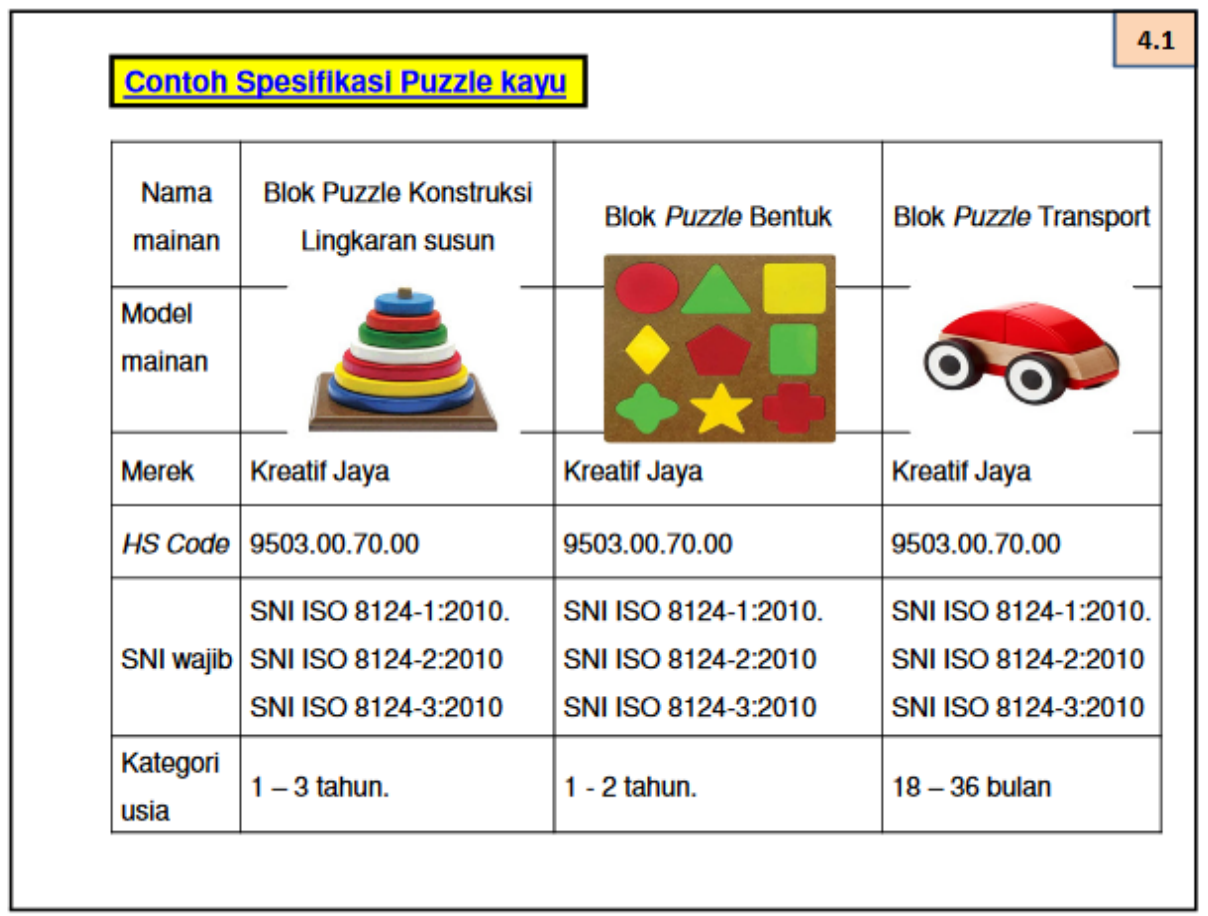

Gambar 4. Contoh Jenis Puzzle

Sumber: SNI ISO 8124-1:2010

Untuk menjelaskannya skema warna, tim menggunakan lingkaran kombinasi warna dari Johannes Ittens, yang diolah lagi oleh tim dengan penggunaan nomor, untuk menjelaskan posisi warna primer, sekunder dan tertier.

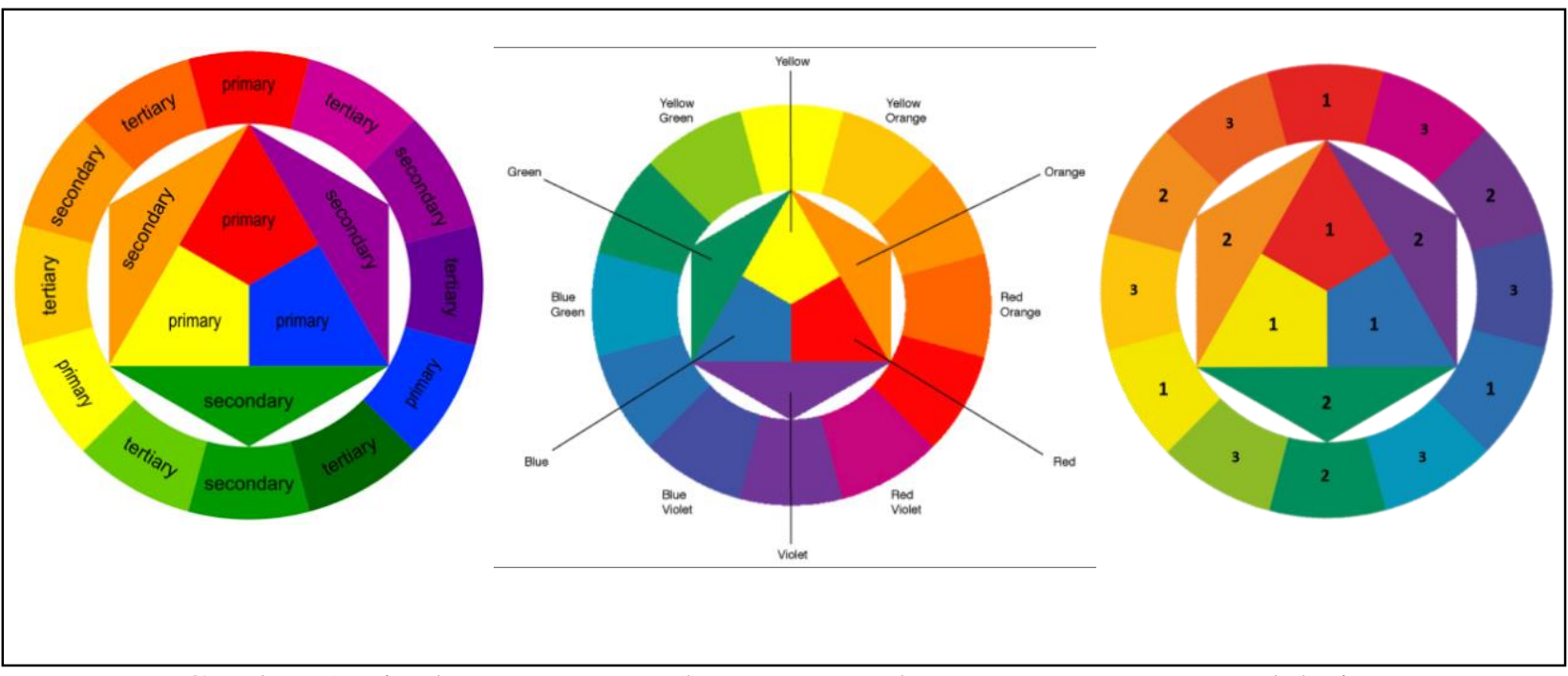

Gambar 5. Lingkaran Warna Johannes Itten dan penomoran warna oleh tim Sumber: olahan tim 


\section{METODE PELAKSANAAN PKM}

Metode pelaksanaan yang diterapkan untuk mencapai luaran yang diterapkan pada kegiatan PKM ini mengacu pendekatan partisipatif, yang melibatkan para pihak dalam menentukan program kegiatan. Sehingga dalam pelaksanaannya melalui beberapa tahapan sebagai berikut:

1) Survey Lapangan.

Survey lapangan dilakukan untuk mengetahui dan mengenal lebih lanjut potensi dan persoalan dari RPTRA Abdi Praja, serta hubungan dan situasi lokasi RPTRA dengan kawasan sekitarnya.

2) Diskusi dan Wawancara.

Diskusi dan wawancara dilakukan kepada Pengelola, Ibu Lurah dan masyarakat pengguna. Diskusi dan wawancara ini dilakukan guna menemukenali persoalan umum, persoalan khusus dan harapan dari pengelola dan masyarakat. Melalui diskusi dan wawancara ini dapat ditemukan solusi khas bagi persoalan yang diajukan.

3) Identifikasi umum kebutuhan RPTRA Abdi Praja agar dapat menunjang keberlanjutan RPTRA. Identifikasi ini bertujuan agar kegiatan PKM dapat kembali digagas menjadi sebuah kegiatan multi tahun yang dapat memiliki dampak dan manfaat terutama bagi masyarakat sekitar. Melalui identifikasi ini diharapkan keberadaan RPTRA juga menjadi lebih berdaya guna baik bagi masyarakat usia kanak-kanak maupun masyarakat lanjut usia. Melalui identifikasi ini diharapkan dapat tersusun daftar kebutuhan berdasarkan urgensi dan prioritas.

4) Identifikasi khusus kebutuhan fisik ruang dan prasarana/ sarana penunjang taman baca. Melalui identifikasi ini diharapkan dapat ditemukan suatu solusi cepat dan tepat bagi pendayagunaan fungsi taman baca RPTRA Abdi Praja

5) Identifikasi khusus kebutuhan peningkatan sumber daya manusia pengelola RPTRA Abdi Praja. Identifikasi ini diharapkan dapat menghasilkan kebutuhan yang signifikan guna mendayagunakan serta meningkatkan kapasitas sumber daya manusia yang bertanggung jawab mengelola taman baca RPTRA Abdi Praja.

6) Penambahan koleksi buku, baik dalam jumlah judul maupun dalam jumlah buku. Kegiatan ini melalui tahap penyeleksian jenis buku yang dibutuhkan, dan pembelian buku baru sesuai klasifikasi yang dibutuhkan.

7) Pengadaan Alat Permainan Edukasi sebagai bagian tak terpisahan dari sebuah taman baca di RPTRA. Keberadaan alat ini juga diharapkan dapat memperkuat fungsi "Ramah Anak" dari RPTRA Abdi Praja berupa puzzle yang nantinya dapat dicat oleh peserta anak-anak, tujuannya adalah memberikan edukasi kepada peserta untuk belajar tentang warna dan proses pewarnaan.

8) Pembuatan puzzle, didahului dengan pencarian model dan pola puzzle serta pembelian bahan dasar puzzle. Model puzzle yang digunakan adalah bentuk imaji yang akrab dengan anak, tidak mengandung unsur kekerasan dan penyinggungan terhadap SARA (suku, agama, ras dan antar golongan). Untuk itu model berbentuk singa, kura-kura, dinosaurus dan gajah, serta dua model rumah sederhana dpilih untuk dijadikan model puzzle yang akan diwarnai. Bahan dasar bagi puzzle harus memenuhi kriteria dan persyaratan dasar bagi pembuatan mainan anak. Bahan dasar cat kayu yang digunakan harus non toxic atau tidak mengandung bahan beracun. Cat hanya menggunakan warna primer karena anak-anak akan diajari mengenal warna dan bagaimana mencampur warna sampai mendapatkan warna yang diinginkan. 


\section{HASIL DAN PEMBAHASAN}

Pelaksanaan kegiatan PKM ini menghasilkan antara lain:

1. Pelatihan mengenal jenis warna, mengenal cara mencapur warna dan teknik mewarnai menggunakan cat akrilik tak beracun. Kegiatan ini diikuti oleh lebih dari 35 anak berusia mulai 6 sampai 11 tahun, yang berasal dari permukiman sekitar RPTRA Abdi Praja. Sebelumnya peserta terdaftar adalah 24 anak, namun pada saat pelaksanaan, diikuti lebih dari 30 anak, yang berdampak pada proses pembelajaran terutama rasio tenaga pengajar (3 Dosen dan 2 Mahasiswa) yang tidak memadai. Peserta mempunyai beragam karakter, walaupun sebagian besar antusias dan tertib, namun terdapat beberapa anak yang sering mengganggu temannya, cenderung tidak patuh dan agresif. Dalam hal ini, peran ibu-ibu pengelola dirasakan sangat membantu kelancaran pelaksanaan kegiatan.
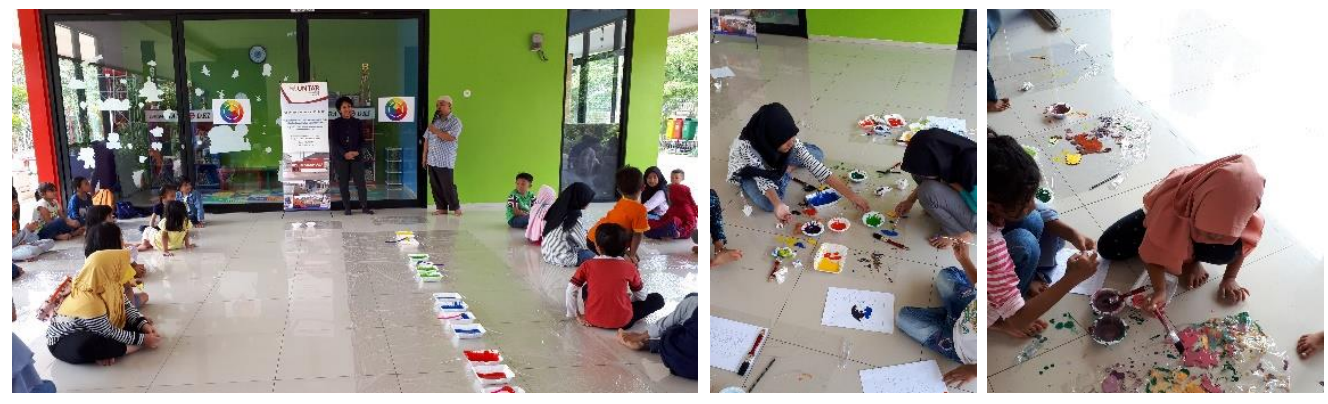

Gambar 6. Pelatihan mengenal dan mencampur warna Sumber: Dokumentasi Pribadi

2. Praktek mewarnai puzzle. Dengan tujuan setiap peserta mendapat pengetahuan dan keterampilan yang merata, dibentuk kelompok yang masing masing terdiri atas 4 anak. Setiap anak dalam kelompok diberi tugas mencampurkan warna sesuai skema lingkaran warna yang diajarkan. Warna-warna tersebut digunakan mewarnai puzzle yang telah disediakan oleh Tim PKM Arsitektur Untar. Kegiatan ini menghasilkan 12 set puzzle berwarna untuk melengkapi sarana bermain edukatif di perpustakaan.
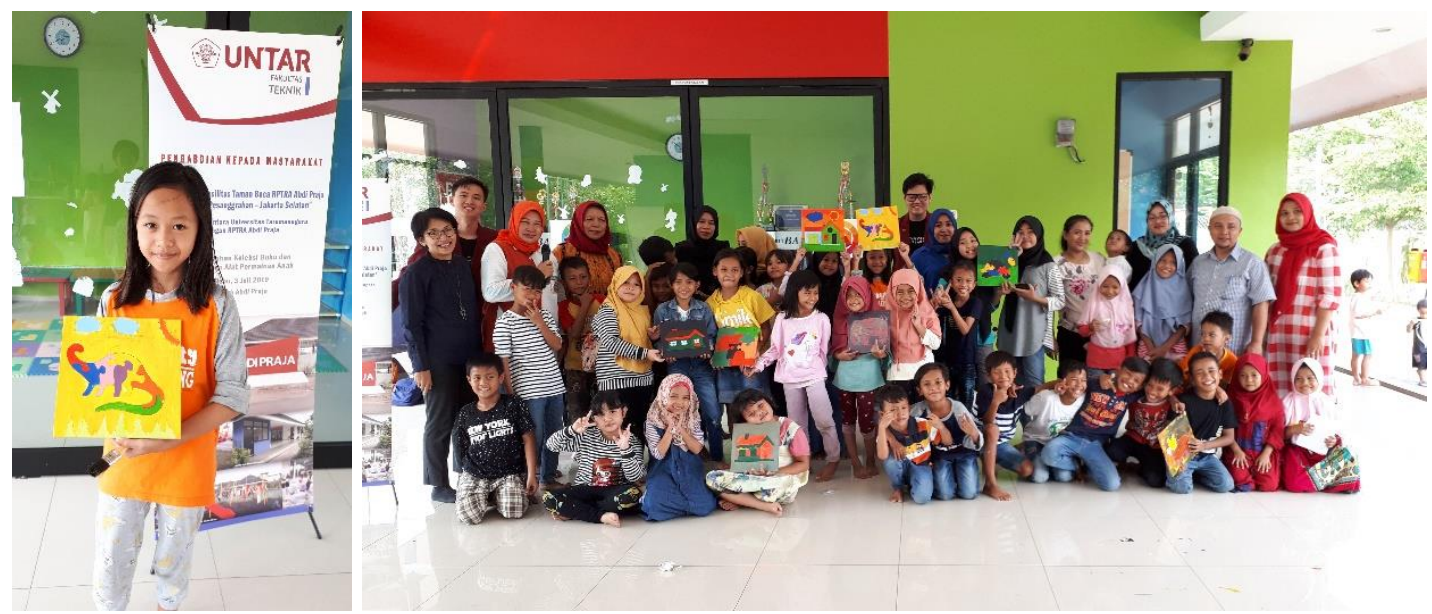

Gambar 7. Hasil Pengaplikasian mewarnai puzzle Sumber: Dokumentasi Pribadi 
3. Menambah koleksi buku di taman baca. Untuk menambah koleksi taman baca, diawali dengan proses seleksi sesuai kebutuhan Mitra. Tim PKM melakukan pembelian 20 judul buku baru senilai Rp. 1.940.000. Buku yang dibeli terbagi atas dua bahasa yaitu Bahasa Inggris dan Bahasa Indonesia dengan tiga kategori. Adapun kategori yang digunakan adalah sebagai berikut : buku anak- anak; buku remaja; buku dewasa dan lain-lain. Adapun penambahan koleksi taman baca juga dilakukan dengan memberikan buku bekas layak pakai. Sebagian besar buku bekas layak pakai yang diberikan adalah buku yang menunjang pelajaran sekolah seperti buku soal-soal ujian nasional, buku rangkuman mata pelajaran tertentu seperti buku rangkuman Biologi dan buku rangkuman matematika.

Serah terima buku baru dilakukan kepada Ketua pengelola RPTRA Abdi Praja, Bapak Suwondho oleh Ketua Tim Pelaksana PKM, Nina Carina S.T., M.T.

\section{KESIMPULAN DAN SARAN}

Minat dan antusiasme anak untuk terlibat dalam kegiatan workshop mewarnai dan membuat puzzle terlihat sangat besar. Walaupun banyaknya peserta membuat aktivitas workshop kurang tertangani dengan maksimal. Namun ini memperlihatkan bahwa pengadaan workshop dapat membuat RPTRA menjadi lebih dekat serta bermanfaat bagi pengunjung usia kanak-kanak.

Penambahan koleksi buku yang menarik juga penambahan alat permaianan anak edukatif berupa puzzle yang dibuat sendiri oleh anak-anak secara nyata membuat taman baca lebih sering dikunjungi dan dimanfaatkan sebagaimana fungsinya. Hal ini merupakan sebuah peningkatan dibandingkan sebelumnya, dimana anak-anak dan orangtua hanya hadir di taman baca untuk mendinginkan diri dari panasnya udara luar. Namun agar RPTRA Abdi Praja dapat terus meningkatkan fungsinya sebagai fasilitas ramah anak, pengelola mengharapkan adanya keberlanjutan program sejenis. Dan untuk menjamin lancarnya pelaksanaan workshop yang akan selalu disambut antusiasme banyak anak-anak di sekitar Kawasan RPTRA Abdi Praja, dibutuhkan tim yang terdiri atas lebih banyak orang guna membimbing anak-anak tersebut.

\section{Ucapan Terima Kasih}

Tim mengucapkan terima kasih atas kerjasama dan bantuan Bapak Suwondo dan timnya selaku pengelola RPTRA Abdi Praja, serta pihak Kelurahan Pesanggrahan yang telah memberikan kesempatan, tempat serta dukungan fasilitas dan kata sambutan pada kegiatan ini. Tim juga memberikan apresiasi kepada orangtua dan anak-anak sekitar RPTRA Abdi Praja yang telah turut mensukseskan acara serta kepada Direktorat Penelitian dan Pengabdian kepada Mayarakat Universitas Tarumanagara atas dukungan pendanaan yang diberikan.

\section{REFERENSI}

Badru, Z. (2007). Media dan Sumber Belajar TK. Jakarta: Universitas Terbuka

Itten, J. (1971). The Elements of colors. Van Nostrand reinhold Company, NY

Jones P.B. et.al. Editor. 2005. Architecture and Participation. Spon Press, Taylor \& Francis Group, London and NY.

Peraturan Gubernur 123 tahun 2017 tentang Pengelolaan Dan Kebutuhan Sarana Dan Prasarana Ruang Publik Terpadu Ramah Anak

Syamsuardi. (2012). Penggunaan Alat Permainan Edukatif (APE) di Taman Kanak-Kanak PAUD Polewali Kecamatan Tanete Riattang Barat Kabupaten Bone. Jurnal Publikasi Pendidikan Universitas Negeri Makassar Vol. II, No.1. 25486721.

SNI ISO 8124-1:2010, butir 3.64, Tentang Permainan Puzzle dan Teknik Pembuatannya. 
Wijaya, N.A. \& Tulistyantoro, L. (2016). Perancangan Interior Perpustakaan Anak di Surabaya. Jurnal Intra Vol. 4, No. 2 . 374-385377. 